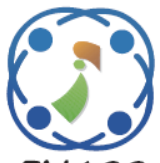

\title{
Analysis of Winding Temperature and Design of Distribution Transformer for Improving Short Circuit Withstand Capability under Renewable Generations Mixed Environment
}

\author{
Boonlert Suechoey $^{1} \quad$ Chongrak Boonseng $^{1} \quad$ Chow Chompooinwai $^{1} \quad$ Chai Chompoo-inwai $^{1 *}$ \\ ${ }^{I}$ Electrical Engineering Department, Faculty of Engineering, \\ King Mongkut's Institute of Technology Ladkrabang, Bangkok, Thailand \\ * Corresponding author's Email: chaichompoo@gmail.com
}

\begin{abstract}
Under renewable generations mixed in today's modern grid system, many of renewable generation resources tend to increase the fault level to an existing power system. Rules and regulation for power equipment and devices need to be revised and updated, of course, no exception for the distribution transformers. This article, therefore, presents the evaluation and analysis of the winding temperature on both loading and short circuit conditions of an oil-immersed distribution transformer and propose the novel transformer design method for improving short circuit withstand capability. In the study, the methodologies of measuring and estimating the winding temperature of the transformer during short circuited are presented and implemented. In the study, various winding parameters are analysed including: the winding temperature, the hottest temperature of the winding after a short circuit, the short circuit current, short circuit force and short circuit duration. The tested and analysed result are benefit for the newly proposed distribution transformer design of a $400 \mathrm{kVA} 3$ phases $50 \mathrm{~Hz} 22 \mathrm{kV}-400 / 230 \mathrm{~V}$, Dyn11. The new design approaches will enable designers to find a weak spot and proper selection of raw materials, such as winding size, insulation thickness and properties of the silicon steel for a better quality of distribution transformer. Moreover, the new design can offer lower winding temperature rise of transformer while loading or experiencing with short circuit conditions meaning that it can prolong transformer insulation and extend transformer lifetime.
\end{abstract}

Keywords: Hottest spot temperature, Temperature rise, Short circuit current, Short circuit force.

\section{Introduction}

Distribution transformer (DT) is an important device in electrical power system. It is not just only the front end equipment to deliver electricity to end consumers but also plays an important role as a system healthy monitoring and indicator. At the present time, under the new environment of renewable generation mixed in smart grid system, an integration of renewable generation resources tend to increase the fault level and cause severe operation issues to an existing power system [1]. The variety of new converter technology in generations and load complexity can also cause power quality issues to a conventional power system. Therefore, the new safety design rules and regulations need to be revised and updated to power equipment, apparatus and devices including both power transformers and distribution transformers. Many articles have been studied about the hot-spot inside distribution transformer and its windings because this is an important factor indicate transformer efficiency, performance and lifetime. In 2008, methodologies of finding transformer winding hot spot while loading was proposed and implemented by [2], and [3] has investigated and compare the algorithm of the hotspot temperature calculation to an experimental test of power transformer in 2015. While [4] used support vector regression to analyse and compared three of transformer top oil temperature modelling, [5] has analysed and compare the hot-spot thermal models of $\mathrm{HV} / \mathrm{LV}$ prefabricated Oil-Immersed 
transformers by using top-oil temperature rise models. In addition, [6] described the application of finite element methods for determining the distribution of losses over windings and determining the value of the hot-spot factor and hot-spot temperature. Researchers in [7] and [8] revealed that external short circuit can produce high current in transformer winding and create high internal forces which are the major cause of damaging transformer. Moreover, [9] has found the impact of transformer's losses from harmonics which can deteriorate transformer lifetime. Hence, it can be seen that many researches aimed focus to transformer's lifetime analysis and study. Researchers in [10] have proposed an assessment on aging model of IEEE/IEC standards for Oil-Immersed transformer by using thermal model to analyse the behaviour transient thermal performance while [11] has defined the smart meter functions required to accurately assess the aging of distribution transformer according to IEEE Std. C57.91 and C57.110. Although many articles have been studied and focus on distribution transformer hot-spot temperature and lifetime, however, no one has been considering the design of DT which includes features to withstand the loading and short circuit conditions among the integration of various renewable generations mixed.

Therefore, this research is not only present new design methods of distribution transformer but also implement the testing, evaluating, and analysing the winding temperature on various loading and short circuit conditions of an oil-immersed distribution transformer. Then, based on analysis results, this research proposes new techniques for improvement and development of distribution transformers design for power system security enhancement and extend transformer's lifetime.

\section{Method of analysis}

Typically, the winding insulation aging depends on the thermal inside the transformer and operating time. The degraded insulation usually occurs at the hottest spot temperature. Therefore, in this study, main focuses aimed to these followings:

\subsection{Specific parameter from a transformer temperature rise test}

In Thailand, the Provincial Electricity Authority of Thailand (PEA) [12], who responses for almost $90 \%$ of distribution system in the country, has issued the regulation and limitation of distribution transformer parameters within specific range. Details of each parameter are shown in following equations:

2.1.1. Average winding temperature rise [13-15]

$$
\begin{aligned}
& \Theta_{w r}=\Theta_{w 2}-\Theta_{a} \\
& \Theta_{w 2}=\frac{R t 2}{R t 1}\left(k+\Theta_{w 1}\right)-k
\end{aligned}
$$

Where;

$\Theta_{w r}$ is average winding rise, ${ }^{\circ} \mathrm{C}$

$\Theta_{a}$ is ambient temperature, ${ }^{\circ} \mathrm{C}$

$\Theta_{w l}$ is initial average winding resistance, ${ }^{\circ} \mathrm{C}$

$\Theta_{w 2}$ is average winding resistance at shutdown, ${ }^{\circ} \mathrm{C}$

$R_{t l}$ is winding resistance at ambient temperature, $\Omega$

$R_{t 2}$ is winding resistance after switch off (graphical extrapolation), $\Omega$

$k=234.5$ for copper, 224.5 for aluminum

\subsubsection{Top oil temperature rise at rated load}

$$
\Theta_{o r}=\Theta_{o}-\Theta_{a}
$$

Where;

$\Theta_{o r}$ is top oil temperature rise at rated load, ${ }^{\circ} \mathrm{C}$

$\Theta_{o}$ is top oil temperature at rated load, ${ }^{\circ} \mathrm{C}$

\subsection{Parameter from transformer short-circuit}

During short circuit condition, following critical parameter need to be calculated [16]

$$
t=\frac{1250}{I^{2}} t
$$

Where;

$t$ is short-circuit current duration, in second $I=I_{s c} / I_{R}$ is symmetrical short-circuit current, in multiples of normal base current

Remark: less than $500 \mathrm{kVA}$. However, for the larger transformer, the duration of the short circuit should not exceed 2 seconds by default.

\subsubsection{Short-circuit current calculation $[13,16]$}

The short circuit current calculation can be calculated as following equations.

1. Symmetrical current can be found from the equation.

$$
I_{S C}=\frac{I_{R}}{Z_{T}+Z_{S}}
$$


Where;

$I_{R}$ is rated current, in rms amperes

$Z_{T}$ is transformer impedance, in per unit

$Z_{S}$ is impedance of the system, in per unit

Remark: This research addresses short circuit current at the terminals of the transformer without change on impedance of the system. (Therefore, Short circuit current is the maximum)

2. Asymmetrical current can be found from the equation.

$$
I_{S C \text { (pkasym) }}=K I_{S C}
$$

Where;

$$
K=\left[1+\left(e^{-(\theta+\pi / 2) r / x}\right) \sin \theta\right] \sqrt{2}
$$

and

$e$ is base of natural logarithm

$\theta$ is $\arctan \mathrm{x} / \mathrm{r}$, in radian

$x / r$ is ratio of effective alternating-current reactance to resistance, both in ohms

3. Calculation of winding temperature during a short circuit

Typically, final winding temperature value $\left(T_{f}\right)$ at the end of short circuit duration can be calculated from Eq. (7).

$$
T_{f}=\left(T_{k}+T_{S}\right) \times m(1+E+0.6 m)+T_{S}
$$

Where;

$m=\frac{\left(w_{S}\right) t}{C\left(T_{k}+T_{S}\right)}$

In Eq. (7), the recommend value of $m$ should be restricted to $m=0.6$ or less. However, for if value of $\mathrm{m}$ excesses than 0.6, $T_{f}$ can be found from Eq. (8).

$$
T_{f}=\left(T_{k}+T_{S}\right)\left[\sqrt{e^{2 m}+E\left(e^{2 m}-1\right)}-1\right]+T_{S}
$$

Where;

$T_{k}$ is 234.5 for copper, 224.5 for aluminum.

$T_{S}$ is Initial temperature. It is equal to following conditions:

(1) $30{ }^{\circ} \mathrm{C}$ ambient temperature plus the average winding rise plus the manufacturer's recommended hottest spot allowance; or

(2) $30{ }^{\circ} \mathrm{C}$ ambient temperature plus the limiting winding hottest spot temperature rise specified for the appropriate type of transformer. $e$ is base of natural logarithm $\approx 2.718$

$E$ is per unit eddy current loss, based on resistance loss $\left(W_{S}\right)$, at starting temperature

$$
E=E_{r}\left[\frac{T_{k}+T_{r}}{T_{k}+T_{s}}\right]^{2}
$$

Where;

$E_{r}$ is per-unit eddy current loss at reference temperature

$T_{r}$ is reference temperature: $20^{\circ} \mathrm{C}$ ambient temperature plus rated average winding rise

$W_{S}$ is short-circuit resistance loss of winding at the starting temperature, in watts per pound of conductor

$$
W_{s}=\frac{W_{r} N^{2}}{M} \times\left(\frac{T_{k}+T_{s}}{T_{k}+T_{r}}\right)
$$

Where;

$W_{r}$ is resistance loss of winding at rated current and reference temperature, in watt

$N$ is symmetrical short circuit magnitude, in times normal rated current

$M$ is weight of winding conductor, in pounds

$C$ is average thermal capacitance per pound of conductor and its associated turn insulation, in wattseconds per degree Celsius. It shall be determined by iteration from either of the following empirical equation:

For copper

$$
C=174+0.0225\left(T_{S}+T_{f}\right)+110\left(\frac{A i}{A c}\right)
$$

For aluminum

$$
C=405+0.1\left(T_{S}+T_{f}\right)+360\left(\frac{A i}{A c}\right)
$$

Where;

$A i$ is cross-sectional area of turn insulation $A c$ is cross-sectional area of conductor

\subsection{Short-circuit force calculation according to IEC 76-5 standard [17]}

\subsubsection{Asymmetrical short circuit current}

The asymmetrical short circuit current will be calculated as follows:

Where; 


$$
I_{S C}=\sqrt{2} \times\left[1+e^{\left(\frac{-\pi R}{X}\right)}\right] \times\left(\frac{I p h}{E z}\right)
$$

Where;

Iph is Rated phase current

$R$ is \% Resistance

$X$ is \% Reactance

$E z$ is Per unit impedance

\subsubsection{Calculation of radial forces}

Axial leakage flux interacts with coil current generating radial force $\left(F_{r a d}\right)$. Radial flux component interacts with coil current generating axial force $\left(F_{a x}\right)$. Both forces directly damage transformer coils. In normal operation, the forces are minimal, but if the transformer experiences short circuit conditions, current and magnetic force will become very high. Thus, short circuit current must be considered when designing a transformer. The radial force can be obtained from Eq. (14)

$$
F_{\text {rad }}=0.628 \times\left[\frac{(N \times I)^{2}}{H_{w}}\right] \times \pi \times D_{m} \times r^{2} \times(k \sqrt{2})^{2} \times 10^{-6}
$$

Where;

$D_{m}$ is mean diameter of the pair of windings, $\mathrm{mm}$.

$H_{w}$ is geometrical average length of windings, $\mathrm{mm}$.

$N$ is number of winding electrical turns, $\mathrm{mm}$.

$I$ is rms value of winding current, A

$r=1 / E Z$ is overcurrent factor

$k=\left[1+e^{\left(\frac{-\pi R}{X}\right)}\right]$ is peak amplitude factor

\subsubsection{Calculation of axial forces}

The value of axial force at short circuit withstand test can be calculated by Eq. (15)

$$
\begin{aligned}
F_{a x}= & 0.628 \times\left[\frac{\left(N \times I^{2}\right)}{H^{2} W}\right] \times \pi \times D_{m} \times\left[d+\frac{a_{1}+a_{2}}{3}\right] \\
& \times(2 K-1) \times r^{2} \times(k \sqrt{2})^{2}+10^{-6}
\end{aligned}
$$

Where;

$d$ is width of the main duct

$a_{1}, a_{2}$ are radial width of winding

The value of hoop stress at short circuit withstand test can be calculated by Eq. (16)

\begin{tabular}{|c|c|c|c|}
\hline \multirow[t]{2}{*}{$\begin{array}{l}\text { Transformer } \\
\text { Type }\end{array}$} & \multirow{2}{*}{$\begin{array}{c}\text { Insulation } \\
\text { system } \\
\text { temperature } \\
\left({ }^{\circ} \mathrm{C}\right) \\
\end{array}$} & \multicolumn{2}{|c|}{$\begin{array}{l}\text { Maximum values of } \\
\theta_{l}\end{array}$} \\
\hline & & Copper & Aluminum \\
\hline Oil-immersed & $105(\mathrm{~A})$ & $250^{\circ} \mathrm{C}$ & $200^{\circ} \mathrm{C}$ \\
\hline
\end{tabular}

$$
\sigma_{t}=0.314 \times\left[\frac{N \times I}{H_{w}}\right] \times D_{m} \times J \times r^{2} \times(k \sqrt{2})^{2} \times 10^{-6}(16)
$$

Table 1. Maximum permissible values of average

temperature of the winding after short circuit $\left(\theta_{l}\right)$

Remark: Refer to $[14,17,19]$

Where;

$\sigma_{t}$ is hoop stress, $\mathrm{N} / \mathrm{mm}^{2}$

\subsection{Calculation of the final winding temperature according to IEC standard}

The highest average temperature $\theta_{l}$ of the winding after short circuit can be calculated by Eq. (17)

For copper

$$
\theta_{1}=\theta_{0}+\frac{\frac{2\left(\theta_{0}+235\right)}{106000}}{J^{2} t}-1
$$

Where;

$\theta_{0}$ is the initial temperature, ${ }^{\circ} \mathrm{C}$

$J$ is the short circuit current density, $\mathrm{A} / \mathrm{mm}^{2}$

$t$ is the duration, seconds.

\section{Transformer testing procedures and tested results}

\subsection{Test procedures and results}

For better test results and accuracy, during the transformer temperature test, following procedures are carefully prepared and implemented [18, 20-21]:

1. The tested transformer is sealed type oilimmersed distribution transformer of $400 \mathrm{kVA} 3 \mathrm{ph}$ $50 \mathrm{~Hz}$ 22000-400/230V Dyn 11.

2. Figs. 1 and 2 show the tested circuit of transformer open circuit and short circuit test respectively. Then, Fig. 3 shows the installation of type $\mathrm{K}$ thermocouples at the different points of transformer windings.

3 . In test procedures, the increasing voltage supply at high side until the total loss (no load + load loss) was constant at $610+3949.3=4559.3$ Watt, from open circuit and short circuit test.

It can be seen from Fig. 4 and Fig. 5 that both temperature on low voltage winding and high voltage winding tend to be constant after 12 hours of loading. Moreover, result clearly revealed that the winding temperature obtained from type $\mathrm{K}$ - 
thermocouple at the top positions give the higher temperature than the bottom or lower coil positions.

However, when compare the temperature of the top winding position (point 11 from Fig. 4 or point 10 from Fig. 5) and the top oil position (point 16 form Fig. 6), it can be found that top winding temperature is higher than top oil temperature for all 12 hours of testing. Therefore, in reality, power engineers usually use top oil temperature to represent and estimate the transformer winding temperature while loading conditions.

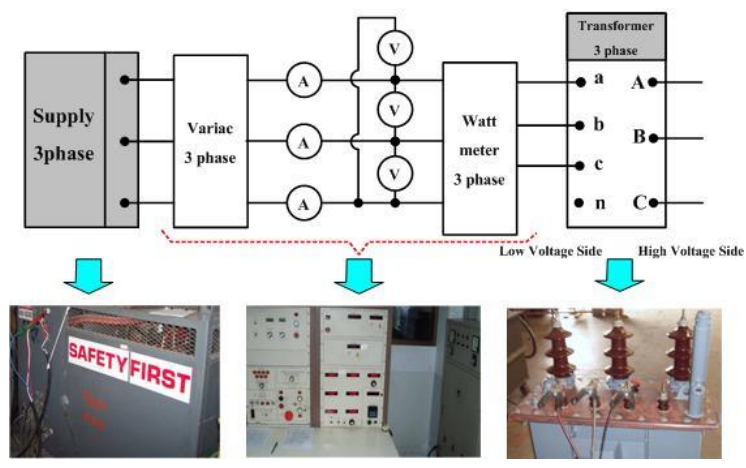

Figure.1 Open circuit test

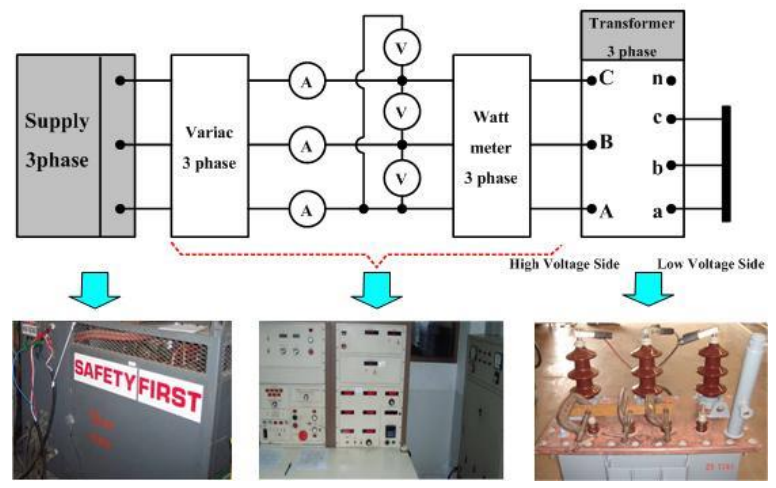

Figure.2 Short circuit test

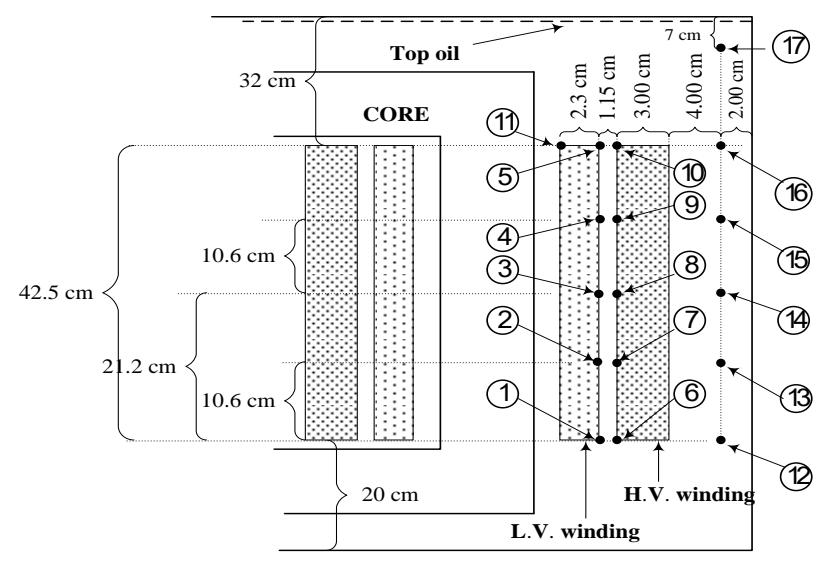

Front view

Figure.3 Thermocouple installation at different points of an oil-immersed distribution transformer $[15,18,22]$

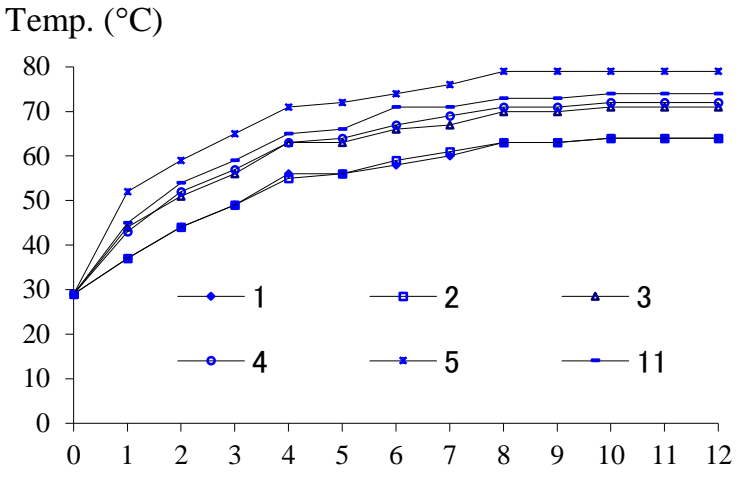

Time (hours)

Figure.4 Low voltage temperature results at points $1,2,3,4,5$ and 11

Temp. $\left({ }^{\circ} \mathrm{C}\right)$

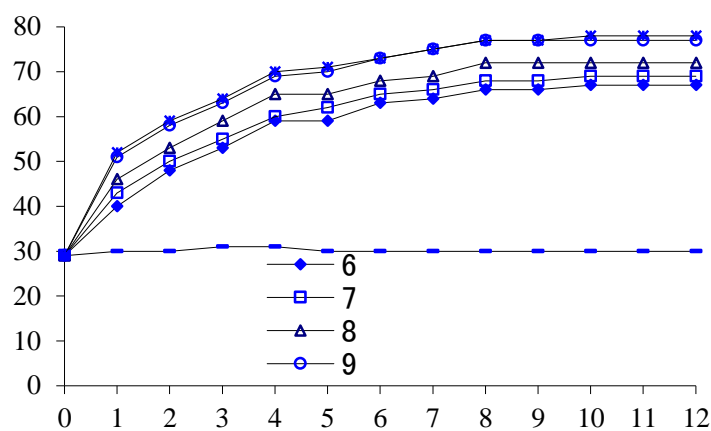

Time (hours)

Figure.5 High voltage temperature results at points $6,7,8,9,10$ and ambient temperature while testing

Temp. $\left({ }^{\circ} \mathrm{C}\right)$

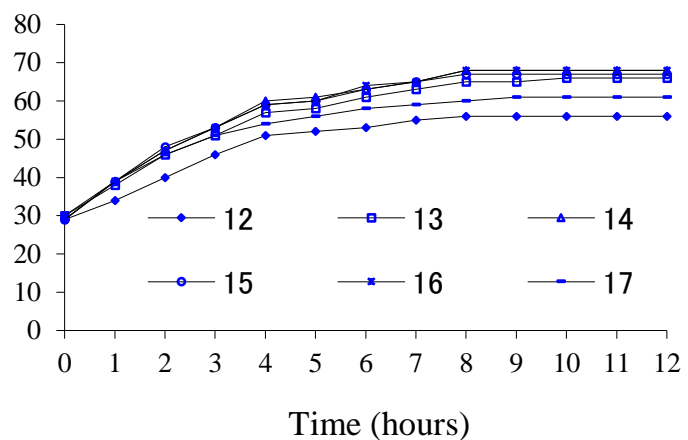

Figure.6 Oil temperature results at points 12-17

Resistance $(\Omega)$

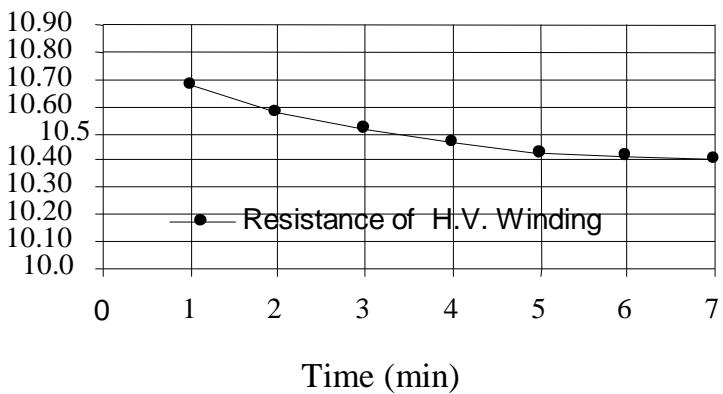

Figure.7 Result of HV-resistance after switch off load 
Moreover, Fig. 7 and Fig. 8 show the winding resistance profiles in both high voltage coil (HV) and low voltage coil (LV) after disconnect load from transformer. The benefit of these two resistances profile will use for calculate the hottest spot of winding temperature.

\subsection{Analysis result}

From the test results, important variables and parameter are evaluated and calculated:

1. $\Theta_{\mathrm{wr}}\left([15,18]\right.$ give not more than $\left.65^{\circ} \mathrm{C}\right)$

2. Top oil temp. $\left(\Theta_{\mathrm{o}}\right)=73^{\circ} \mathrm{C}$ (from [18] specific $\leq 105$ $\left.{ }^{\circ} \mathrm{C}\right)$

3. $\Theta_{\text {or }}=42{ }^{\circ} \mathrm{C}$ (from $[15,18]$ specific $\leq 60{ }^{\circ} \mathrm{C}$ )

The calculation of top oil temperature rise (point 17 of Fig. 3) can be found in Fig. 9 and it can be seen that this temperature is still meet the standard specified in [15].

\subsection{Comparison between conductor hottest spot temperature from testing and calculation}

The comparison between the hottest spot temperature of transformer winding both in low voltage side (LV) and high voltage side (HV) are shown in Figs. 10-11. It can be clearly seen that the hottest temperature obtained from the calculations are pretty closed to the one from the test procedures. Therefore, this finding is an advantage guideline for distribution transformer designer because the designer can use this technique and algorithm to estimate the hottest spot temperature instead of perform the real transformer test in the laboratory.

\section{Resistance $(\mathrm{m} \Omega)$}

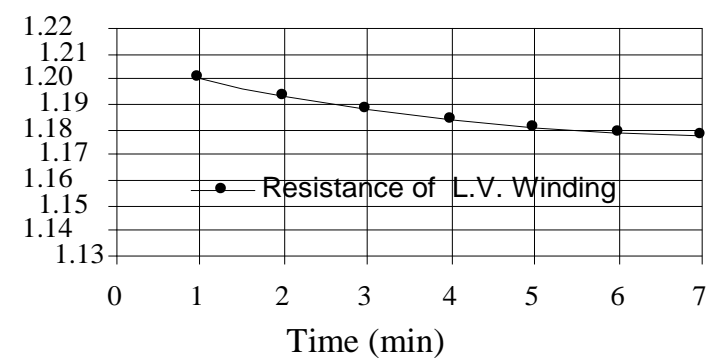

Figure.8 Result of LV-resistance after switch off load

Table 2. Technical data of tested transformer

\begin{tabular}{|l|l|}
\hline Capacity(kVA) & 400 \\
\hline High voltage(V) & 22000 \\
\hline Low voltage(V) & $400 / 230$ \\
\hline No. of phase & 3 \\
\hline Frequency(Hz) & 50 \\
\hline Vector group & Dyn 11 \\
\hline Impedance(\%) & 4.0 \\
\hline Insulation Class & A \\
\hline Cooling type & ONAN \\
\hline
\end{tabular}

Table 3. Calculation results of average winding temperature rise

\begin{tabular}{|l|c|c|}
\hline \multicolumn{1}{|c|}{ Parameter } & LV.winding & HV.winding \\
\hline$\Theta_{\mathrm{w} 1}\left({ }^{\circ} \mathrm{C}\right)$ & 31.00 & 31.00 \\
\hline $\mathrm{R}_{\mathrm{t} 1}(\Omega)$ & 0.00103 & 9.13 \\
\hline$\Theta_{\mathrm{w} 2}\left({ }^{\circ} \mathrm{C}\right)$ & 78.80 & 76.70 \\
\hline $\mathrm{R}_{\mathrm{t} 2}(\Omega)$ & 0.00122 & 10.82 \\
\hline$\Theta_{\mathrm{wr}}\left({ }^{\circ} \mathrm{C}\right)$ & 47.80 & 45.70 \\
\hline
\end{tabular}

Temp. $\left({ }^{\circ} \mathrm{C}\right)$

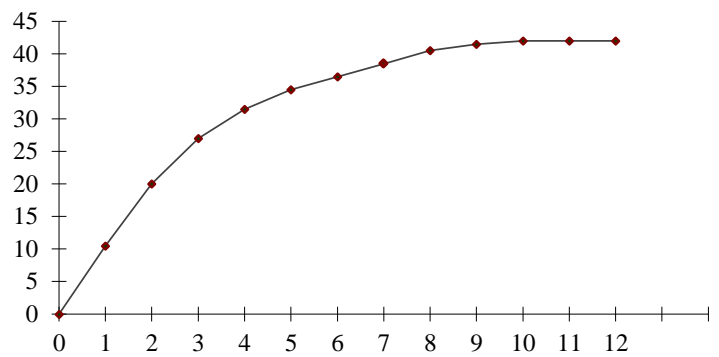

Hours

Figure.9 Top oil temp rise calculation (point 17 of Fig. 3) at rated load

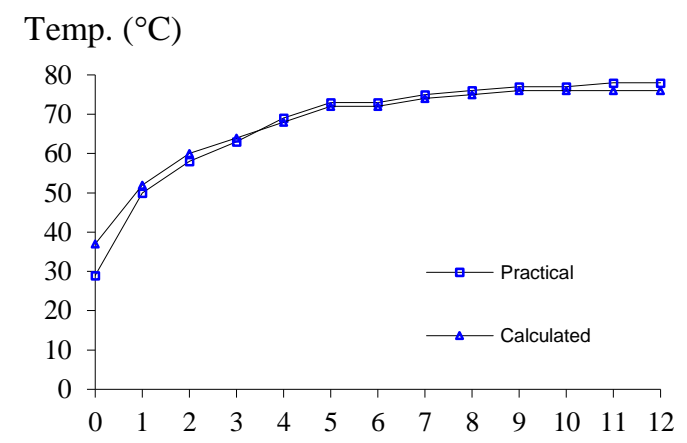

Time (hour)

Figure.10 LV-conductor hottest spot temperature $\left(\Theta_{\mathrm{h}}\right)$ comparison between testing and calculating at full load

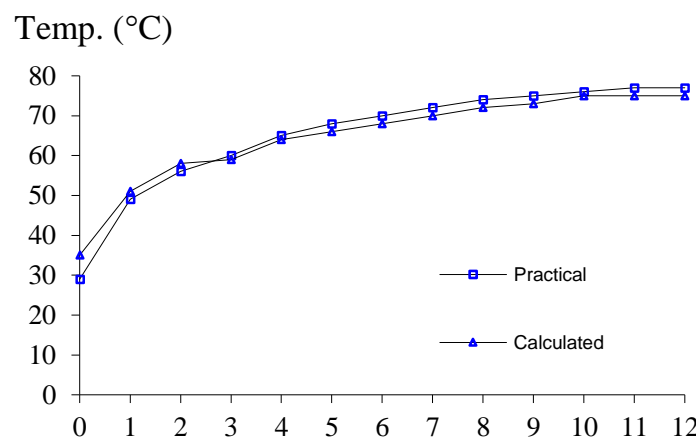

Time (hour)

Figure.11 HV-conductor hottest spot temperature $\left(\Theta_{\mathrm{h}}\right)$ comparison between testing and calculating at full load 
Remark:

1. In Figs. 10 and 11, the assumption for ambient temperature is $30{ }^{\circ} \mathrm{C}$ when calculated hottest spot temperature of conductor $\left(\Theta_{\mathrm{h}}\right)$.

2. From $[16,18],\left(\Theta_{\mathrm{h}}\right) \leq 140^{\circ} \mathrm{C}$ and $\left(\Theta_{\mathrm{hr}}\right) \leq 80^{\circ} \mathrm{C}$

\subsection{Comparison of short circuit withstand parameter between traditional design and the newly proposed design}

In this comparison, the traditional transformer design parameters [12] will be compared to the newly proposed design procedures of distribution transformer which already considering about improving short circuit capability. The newly proposed procedures in Fig. 12 will provide the new set of optimum designed parameters. One can find the numerical comparing result in Tables 4-8.

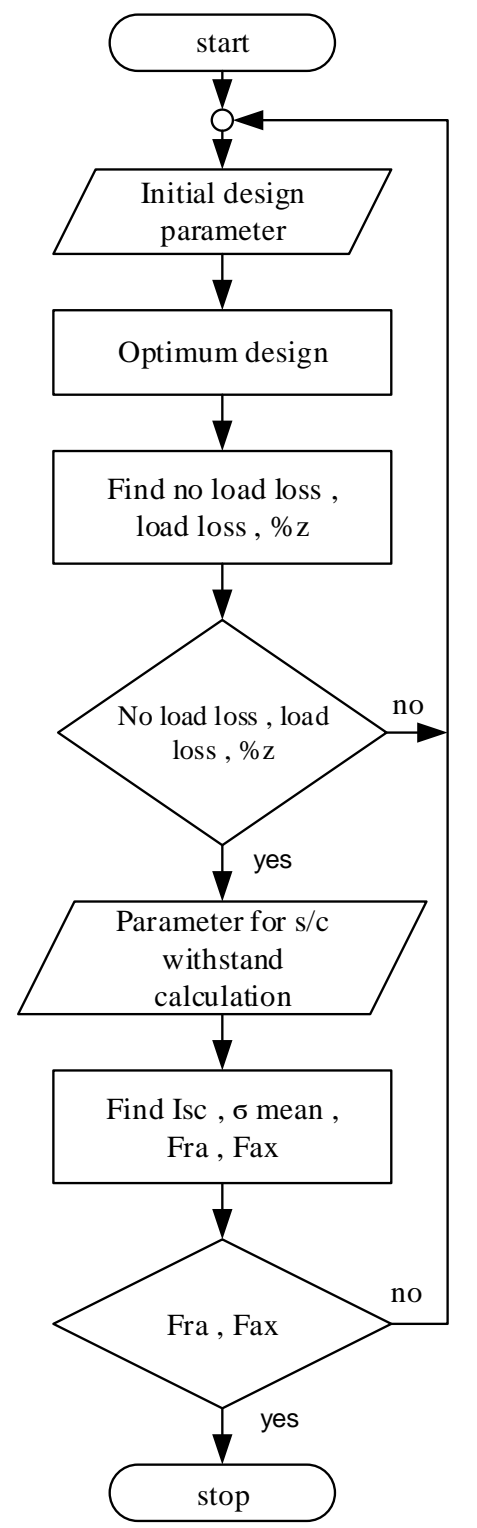

Figure.12 New proposed design algorithm and procedures considering short circuit withstand capability
The top oil temperature rise comparison between original regulation and new regulation of $400 \mathrm{kVA}$ transformers at rated load are presented in Fig. 13.

It is clear that the new proposed design parameter will offer the lower temperature raised compare to the original design regulation.

Although the newly proposed designed algorithm for distribution transformer will offer the benefit in improving the short circuit current capability which will offer more system security. On the other hand, for the distribution utility side and consumer side, transformer losses and transformer lifetime are still the important concerns. Therefore,

Table 4. Comparison of transformer design parameter between original design regulation and the new regulation

\begin{tabular}{|l|c|c|}
\hline \multirow{2}{*}{ Parameter } & \multicolumn{2}{|c|}{400 kVA } \\
\cline { 2 - 3 } & $\begin{array}{c}\text { Original } \\
\text { regulation }\end{array}$ & $\begin{array}{c}\text { New } \\
\text { regulatio } \\
\text { n }\end{array}$ \\
\hline $\begin{array}{l}\text { 1. No Load Loss, W } \\
\text {-Guarantee } \\
\text {-Test }\end{array}$ & 720 & 720 \\
\hline 2. Load Loss, W & 700.5 & 610.0 \\
- Guarantee & 4150 & 4150 \\
- Test & 4040.3 & 3949.3 \\
\hline 3. Total loss , W & 4740.3 & 4559.3 \\
\hline 4. Hottest-spot of top oil, ${ }^{\circ} \mathrm{C}$ & 81.0 & 73.0 \\
\hline 5. Hottest-spot of HV.wdg., ${ }^{\circ} \mathrm{C}$ & 88.3 & 76.7 \\
\hline 6. Hottest-spot of LV.wdg., ${ }^{\circ} \mathrm{C}$ & 89.8 & 78.8 \\
\hline 7. Top oil Temp. rise, ${ }^{\circ} \mathrm{C}$ & & \\
- Guarantee & 60 & 60 \\
- Test & 51.0 & 42.0 \\
\hline 8. Winding Temp. rise, ${ }^{\circ} \mathrm{C}$ & & \\
- Guarantee & 65 & 65 \\
- HV. Winding & 60.3 & 45.7 \\
- LV. Winding & 61.8 & 47.8 \\
\hline
\end{tabular}

Table 5. Parameter required for calculation at short circuit withstand test (HV side)

\begin{tabular}{|l|c|c|}
\hline \multirow{2}{*}{ Parameter } & \multicolumn{2}{c|}{ High voltage side } \\
\cline { 2 - 3 } & Original & New \\
\hline Reactance , \% & 3.77 & 4.18 \\
\hline Resistance, \% & 1.11 & 1.10 \\
\hline Per unit impedance & 0.00393 & 0.00432 \\
\hline $\begin{array}{l}\text { Resistance per phase at 75 } \\
{ }^{\circ} \mathrm{C}, \text { Ohm/phase }\end{array}$ & 11.82 & 11.05 \\
\hline Winding height (mm) : Hw & 425 & 365 \\
\hline Number of turn per limb : N & 2700 & 2600 \\
\hline $\begin{array}{l}\text { Current density of winding } \\
\left(\text { A/mm }{ }^{2}\right): \text { J }\end{array}$ & 2.38 & 2.52 \\
\hline $\begin{array}{l}\text { Mean diameter of winding } \\
\text { (mm) : Dm }\end{array}$ & 285 & 162 \\
\hline Radial of winding 1 : a1 & - & - \\
\hline Radial of winding 2 : a2 & 31 & 30 \\
\hline Width of main duct (mm) : d & 12 & 11.5 \\
\hline
\end{tabular}


Table 6. Parameter required for calculation at short circuit withstand test (LV side)

\begin{tabular}{|l|c|c|}
\hline \multirow{2}{*}{ Parameter } & \multicolumn{2}{c|}{ Low voltage side } \\
\cline { 2 - 3 } & Original & New \\
\hline Reactance, \% & 3.77 & 4.18 \\
\hline Resistance, \% & 1.11 & 1.10 \\
\hline Per unit impedance & 0.00393 & 0.00432 \\
\hline $\begin{array}{l}\text { Resistance per phase at } 75^{\circ} \mathrm{C}, \\
\text { Ohm/phase }\end{array}$ & 0.00146 & 0.00125 \\
\hline Winding height $(\mathrm{mm}): \mathrm{Hw}$ & 465 & 385 \\
\hline Number of turn per limb : N & 27 & 26 \\
\hline $\begin{array}{l}\text { Current density of winding } \\
\left(\text { A/mm }{ }^{2}\right): \mathrm{J}\end{array}$ & 2.61 & 2.48 \\
\hline $\begin{array}{l}\text { Mean diameter of winding } \\
\text { (mm) : Dm }\end{array}$ & 207 & 212 \\
\hline Radial of winding 1 : a1 & 22 & 23 \\
\hline Radial of winding 2 : a2 & - & - \\
\hline Width of main duct (mm) : d & 12 & 11.5 \\
\hline
\end{tabular}

Table 7. Forces and final temperature calculation results at short circuit withstand test (HV side)

\begin{tabular}{|l|l|l|}
\hline \multirow{2}{*}{\multicolumn{1}{|c|}{ Parameter }} & \multicolumn{2}{c|}{ HV side } \\
\cline { 2 - 3 } & \multicolumn{1}{c|}{ Original } & \multicolumn{1}{c|}{ New } \\
\hline $\begin{array}{l}\text { Asymmetrical short circuit } \\
\text { current (A) }\end{array}$ & 304.57 & 285.20 \\
\hline$\sigma_{t}$ & 34.53 & 34.40 \\
\hline Radial force & 1491.49 & 1351.47 \\
\hline Axial force & 99.45 & 98.80 \\
\hline Final winding temp. $\left({ }^{\circ} \mathrm{C}\right)$ & 155.55 & 151.65 \\
\hline
\end{tabular}

Table 8. Forces and final temperature calculation results at short circuit withstand test (LV side)

\begin{tabular}{|l|c|c|}
\hline \multirow{2}{*}{ Parameter } & \multicolumn{2}{c|}{ LV side } \\
\cline { 2 - 3 } & Original & New \\
\hline $\begin{array}{l}\text { Asymmetrical short circuit } \\
\text { current (A) }\end{array}$ & 29015.09 & 27169.38 \\
\hline$\sigma_{t}$ & 23.77 & 22.32 \\
\hline Radial force & 892.06 & 848.97 \\
\hline Axial force & 62.69 & 59.26 \\
\hline Final winding temp. $\left({ }^{\circ} \mathrm{C}\right)$ & 166.73 & 150.09 \\
\hline
\end{tabular}

\section{Temp. $\left({ }^{\circ} \mathrm{C}\right)$}

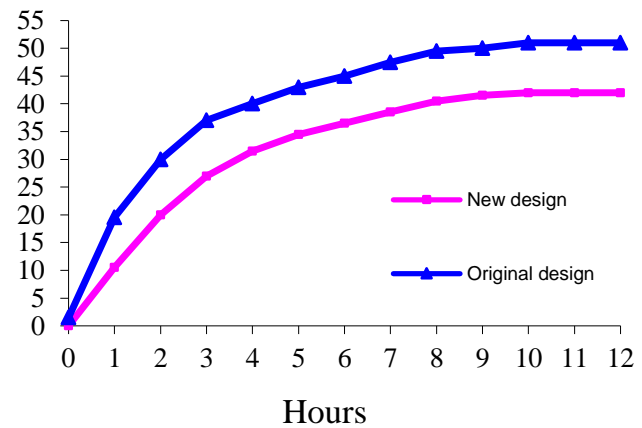

Figure.13 Top oil temperature rise comparison between original and new regulation $400 \mathrm{kVA}$ at rated load

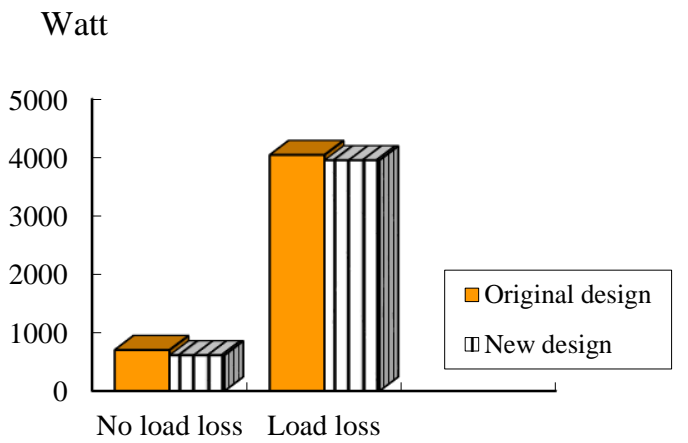

Loss

Figure.14 Loss comparison between original design compared to the newly proposed design/regulation

Temp. $\left({ }^{\circ} \mathrm{C}\right)$

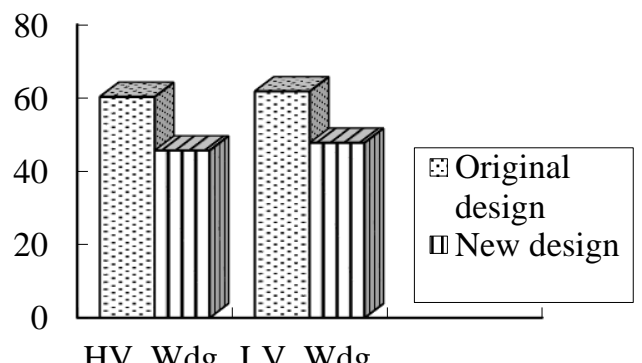

Winding

Figure.15 Winding temperature rise comparison between original and new regulation designs

Fig. 14 shows the loss comparison between original design and new proposed design. It is clear that the newly proposed design will offer lower losses which results in a better economics value, while Fig. 15 shows that the newly proposed design techniques will offer lower winding temperature rise which means a longer transformer lifetime.

\section{Conclusion}

From the test and analysis result, it is clear that information of temperatures obtained from the tested transformer during loading and short circuit will benefit for a newly proposed design algorithm to obtain more safety and economically of distribution transformer. In addition, result from Fig. 10 and 11, clearly show that it is only small difference between the measuring result and calculating result, therefore, this similarity trend can be used as a guideline for the distribution transformer design.

In conclusion, with the main finding and newly proposed design algorithm of this research, it can lower winding temperature of distribution transformer while loading or experiencing with short 
circuit conditions which mean it can prolong transformer insulation and extend transformer lifecycle time. Therefore, it not only provides more safety transformer to reinforce power system security but also provides a lower losses transformer result in economics benefit for both utilities and end users in distribution system.

\section{Acknowledgments}

The author would like to Thank T.D.Transformer Co., Ltd. and Phongpimarn Electric Co., Ltd. Thailand for supporting data and equipment of this work and would like to give a special thanks to both of the Electrical Engineering Departments at KMITL and Southeast Asia University for part of the financial supports.

\section{References}

[1] C. Chompoo-inwai, W.J. Lee, P. Fuangfoo, M. Williams, and J. Liao, "System Impact Study for the Interconnection of Wind Generation and Utility System", IEEE Transaction of Industrial Application, Vol.41, No.1, pp.163-168, 2005.

[2] T.C.B.N. Assuncao, J.L. Silvino, and P. Resende, "Transformer Top-Oil Temperature Modeling and Simulation", International Journal of Energy and Power Engineering, Vol.2, No.2, pp.958-963, 2008.

[3] A.Y. Arabul, I. Senol, F.K. Arabul, M.G. Aydeniz, Y. Oner, and G. Kalkan, "An Investigation on Hot-Spot Temperature Calculation Methods of Power Transformers", International Journal of Energy and Power Engineering, Vol.9, No.8, pp.1036-1040, 2015.

[4] T. Qian, W.H. Tang, W.J. Jin, L.Gan, Y.Q. Liu, and G.J. Lu, "Comparisons of Transformer Top Oil Temperature Calculation Models Using Support Vector Regression Optimized by Genetic Algorithm", In: Proc. of the 24 International Conf. on Electricity Distribution, Glasgow, paper 0539, 2017.

[5] A. Mamizadeh and I. Iskender, "Analyzing and Comparing the Hot-spot Thermal Models of HV/LV Prefabricated and Outdoor OilImmersed Power Transformers", World Academic of Science, Engineering and Technology, Vol.6, No.1, pp.34-39, 2012.

[6] Z. Radakovic, U. Radoman, and P. Kostic, "Decomposition of the Hot-Spot Factor", IEEE Transaction on Power Delivery, Vol.30, No.1, pp.403-411, 2015.

[7] R.P.P. Smeets, L.H.TE. Paske, P.P. Leufkens, and T.F. Ogelberg, "Thirteen Years Test Experience with Short-Circuit withstand
Capability of Large Power Transformer", In: Proc. of Southern Africa Regional Conference, pp.1-7, 2009.

[8] P. Geno Peter, "Calculations for Short Circuit Withstand Capability of a Distribution Transformer", International Journal of Advancements in Technology, Vol.2, No.1, pp.142-150, 2011.

[9] R. UI Hassan, U.T. Shami, and A. Safdar, "Evaluation of Losses and Life of Distribution Transformer under Non-linear Load using Wavelet Transform", In: Proc. of International Conf. on the Pakistan Academy of Sciences, pp.309-317, 2016.

[10] Y. Bicen, Y. Cilliyuz, F. Aras, and G. Aydugan, "An Assessment on Aging Model of IEEE/IEC Standards for Natural and Mineral OilImmersed Transformer", In: Proc. of IEEE International Conference on Dielectric Liquids, pp.1-4, 2011.

[11] K.D. McBee and M.G. Simoes, "General Smart Meter Guidelines to Accurately Assess the Aging of Distribution Transformer", IEEE Transactions on Smart Grid, Vol.5, No.6, pp.2967-2979, 2014.

[12] Provincial Electricity Authority Thailand (PEA), Three-Phase Transformer for $22 \mathrm{kV}$ and $33 k V$ Distribution Systems with Ability to Withstand Short Circuit, Specification No. RTRN-035/2558, 2015.

[13] B. Suechoey, N. Chotiwanaporn, P. Jayasak, and C. Chompoo-inwai, "Proposition of Individual Guide for Distribution Transformer Design to Withstand Short Circuit Condition", In: Proc. of the 20 $0^{\text {th }}$ ICEE International Conference on Electrical Engineering, pp.1-6, 2014.

[14] B. Suechoey, W. Tangsrianukul, M. Leelajinda, and C. Chompoo-inwai, "Novel Techniques for Improving Short Circuit Withstand Capability of Distribution Transformer Considering Short Circuit Force and Winding Temperature", In: Proc. of the $21^{\text {th }}$ ICEE International Conference on Electrical Engineering, pp.1-4, 2015.

[15] IEC 60076-2, Power Transformer Part 2: Temperature Rise, 2011.

[16] ANSI/IEEE C57.91, IEEE Guide for Loading Mineral Oil-Immersed Overhead and Pad Mounted Distribution Transformer Rated 500 $k V A$ and Less with $65^{\circ} \mathrm{C}$ or $55^{\circ} \mathrm{C}$ Average Winding Rise, 1995.

[17] IEC 60076-5, Power Transformer Part 5: Ability to Withstand Short Circuit, 2006. 
[18] IEC 354, Loading Guide for Oil-Immersed Power Transformer, 2006.

[19] ANSI/IEEE C57.12.00, American National Standard IEEE Standard General Requirements for Liquid-Immersed Distribution, Power, and Regulating Transformers, 2010.

[20] Bharat Heavy Electrical Ltd., Transformer, Tata McGrew-Hill Publishing Co. Ltd., New Delhi, $2^{\text {nd }}$ Edition, 2003.

[21] S. Tadsuan, B. Suechoey, V. Kinnares, S. Bunjongjit, and N. Kritsanajinda, "Testing of Temperature at Conductor and Oil of Mineral Oil-Immersed Transformer in order to be Criterion for Transformer Design", KMUTT Research and Development Journal, Vol.23, No.2, pp.59-77, 2000.

[22] B. Suechoey, S. Tadsuan, C. Thammarat, and M. Leelajindakrairerk, "An Analysis of Temperature and Pressure on Loading OilImmersed Distribution Transformer", In: Proc. of the $7^{\text {th }}$ International Power Engineering Conference, pp.1-5, 2005. 